\title{
PENGARUH PERBEDAAN METODE PENGERINGAN TERHADAP KARAKTERISTIK SENSORI DAN KIMIAWI TAPE KETAN HITAM INSTAN
}

\author{
The Effect of Different Drying Methods On Sensory and Chemical Characteristics of \\ Fermented Glutinous Rice-Instant (Indonesian Tape Ketan)
}

\author{
Widia Putri Audia ${ }^{1}$, M.N. Handayani ${ }^{2}$ \\ 1,2 Program Studi Pendidikan Teknologi Agroindustri, \\ Fakultas Pendidikan Teknologi dan Kejuruan, Universitas Pendidikan Indonesia \\ E-mail: mustika@upi.edu
}

\begin{abstract}
ABSTRAK
Pengeringan alami dengan cara penjemuran pada tape ketan hitam instan diduga memicu terjadinya cross linking yang menyebabkan kerusakan produk. Tujuan penelitian ini adalah (1) mengetahui karakteristik sensori dan kimiawi tape ketan hitam instan yang dikeringkan dengan penjemuran, menggunakan oven, dan dengan menggunakan microwave oven; (2) mengetahui efektivitas pengeringan dalam mengendalikan mikroorganisme pada pembuatan tape ketan hitam instan. Penelitian ini menggunakan metode Rancangan Acak Lengkap (RAL) dengan tiga perlakuan pengeringan, yakni metode pengeringan penjemuran, oven dan microwave oven. Hasil penelitian menunjukkan bahwa tape ketan hitam instan yang dikeringkan dengan penjemuran paling disukai konsumen pada atribut warna dan aroma (untuk sampel kering sebelum diseduh), atribut rasa, tekstur dan kenampakan (untuk sampel sesudah diseduh). Karakteristik kimia tape ketan hitam instan yang dikeringkan dengan penjemuran (kadar air 7,43\%; kadar alkohol 0,39\%); oven (kadar air 7,57\%; kadar alkohol 0,26\%); microwave oven (kadar air 6,35\%; kadar alkohol 0,35\%). Pengeringan menggunakan oven dan microwave oven dapat mengendalikan mikroorganisme pada tape ketan hitam instan.
\end{abstract}

Kata Kunci: microwave, pengeringan, penjemuran, oven, tape ketan hitam instan

\section{ABSTRACT}

Natural drying under sunlight on Indonesia tape ketan (fermented glutinous rice) may provoke cross-linking which causes damage to the product. The purpose of this study were (1) find out the sensory and chemical characteristics of tape ketan after drying under sunlight, oven, and microwave oven; (2) determine the effectiveness of drying in controlling microorganisms in the manufacture of tape ketan. This study used a completely randomized design with three treatments of drying methods: under sunlight, oven and microwave oven. The results showed that sensory characteristics of fermented glutinous rice- instant which drained under sunlight was the most preferred by consumers on color and aroma attributes (for samples dried before brewed), the attributes of flavor, texture and appearance (for a sample after brewed). The chemical characteristics of fermented glutinous rice-instant which drained under sunlight (water content of $7.43 \%$; $0.39 \%$ alcohol content), using oven (moisture content $7.57 \% ; 0.26 \%$ alcohol content) and using microwave oven (water content of $6.35 \% ; 0.35 \%$ alcohol content). Drying using oven and microwave oven are able to control microorganisms at fermented glutinous rice-instant (Indonesian tape ketan).

Keywords : drying, fermented glutinous rice, microwave, oven 


\section{PENDAHULUAN}

Tape ketan hitam merupakan salah satu makanan tradisional Indonesia yang dibuat dengan cara memfermentasikan beras ketan hitam menggunakan ragi tape. Mikroorganisme yang terkandung pada ragi tape diantaranya adalah Amylomyces rouxii, Endomycopsis chodati, Saccharomyces cereviseae, dan Hansenula. Khamir Saccharomyces cervicae memiliki kemampuan dalam mengubah karbohidrat (fruktosa dan glukosa) menjadi alkohol dan karbondioksida (Syafridawati, 1991). Tape ketan hitam cukup populer dan digemari oleh masyarakat. Namun demikian, masa simpan tape tidak terlalu lama (Adipura, 2014). Masa simpan tape ketan dapat ditingkatkan menjadi 688,4 hari (1 tahun 9 bulan) dengan cara sterilisasi pada suhu $121^{\circ} \mathrm{C}$ selama 10 menit, kemudian tape ketan disimpan pada suhu $25^{\circ} \mathrm{C}$ (Haryati, dkk., 2015).

Kelompok UPPKS (Usaha Peningkatan Pendapatan Keluarga Sejahtera) Kenanga Desa Citalem Kecamatan Cipongkor Kabupaten Bandung Barat memproduksi tape ketan hitam instan dengan brand "Peuyeum Keke (Ketan Kering)". Tape ini diproduksi dengan mengeringkan tape selama 3-5 hari di bawah sinar matahari untuk meningkatkan masa simpannya. Pengeringan dengan matahari langsung (penjemuran) merupakan proses pengeringan yang paling ekonomis dan paling mudah dilakukan (Winangsi, dkk., 2013). Namun demikian, pengeringan dengan penjemuran memiliki beberapa kekurangan, yaitu dapat terkontaminasi kerikil, debu dan bakteri. Selain itu penjemuran membutuhkan waktu yang lama (Apriadi, 2011) juga dikhawatirkan menimbulkan cross linking antara mikroorganisme yang terdapat dalam tape tersebut dengan mikroorganisme patogen yang tersebar di udara sehingga menyebabkan kerusakan produk tape ketan hitam instan. Sinar ultra violet dari matahari juga menimbulkan kerusakan pada kandungan kimia bahan yang dikeringkan (Pramono, 2006).

Kelemahan pengeringan dengan penjemuran dapat dikurangi dengan menggunakan alat pengering yang memanfaatkan prinsip tenaga listrik (oven listrik), tenaga gelombang elektromagnetik (microwave oven) ataupun pengeringan beku (freeze drier). Pengeringan dengan alat pengering akan lebih aman dan dapat mengantisipasi kontaminasi dari kerikil, debu, dan mikroorganisme patogen. Oven dan microwave oven adalah contoh alat pemanas dan pengering yang diaplikasikan untuk penggunaan rumah tangga (Datta, 2002). Microwave oven menggunakan radiasi gelombang mikro yang diserap oleh molekul air dan zat lain dalam makanan yang menyebabkan timbul energi panas (Maskan, 2000). Oven menempatkan sumber panas di luar makanan dan meningkatkan suhu dari luar ke bagian dalam makanan (Winangsih dkk., 2013). Kedua alat pengering ini lebih tertutup sehingga aman digunakan untuk bahan makanan yang rentan terjadinya kontaminasi silang dengan mikroorganisme patogen seperti tape ketan hitam. Selain itu, dengan menggunakan oven dan microwave oven diharapkan dapat mempersingkat waktu pengeringan. Penelitian ini bertujuan untuk (1) mengetahui karakteristik sensori dan kimiawi tape ketan hitam instan yang dikeringkan dengan menggunakan penjemuran, oven dan microwave oven; (2) mengetahui efektivitas pengeringan menggunakan oven dan microwave oven dalam mengendalikan mikroorganisme pada tape ketan hitam instan.

\section{METODE}

Bahan utama yang digunakan dalam penelitian ini adalah tape ketan hitam produksi UPPKS Kenanga Kecamatan Cipongkor Kabupaten Bandung Barat yang telah difermentasi selama 3 hari. Bahan yang digunakan untuk analisis adalah aquades, larutan $\mathrm{NaOH}$ standar, indikator phenoptalein, media PCA (Plate Count Agar), dan NaCl steril. Alat yang digunakan meliputi oven, microwave oven, desikator, timbangan, loyang, cawan porselen, timbangan analitik, tabung reaksi, cawan petri, inkubator, bunsen, termometer, pipet ukur, Erlenmeyer dan buret.

Metode yang digunakan dalam penelitian ini adalah eksperimen dengan rancangan acak lengkap (RAL). Perlakuan pada penelitian ini adalah perbedaan cara pengeringan yaitu penjemuran, pengeringan dengan oven, dan pengeringan dengan microwave oven. Pengeringan dengan penjemuran dilakukan dengan meletakkan tape ketan hitam di atas loyang kemudian 
menjemurnya di bawah sinar matahari selama 3 hari. Pengeringan dengan menggunakan oven dilakukan dengan meletakkan tape ketan hitam di atas loyang kemudian mengeringkannya pada suhu $50^{\circ} \mathrm{C}$ selama $6-8 \mathrm{jam}$. Pengeringan dengan menggunakan microwave oven dilakukan dengan meletakkan tape ketan hitam di atas piring kemudian mengeringkannya pada piring merek Legacy berstandar SNI dan Microwave ware selama 40 - 45 menit pada $180 \mathrm{~W}$.

Tape ketan hitam yang telah dikeringkan kemudian dianalisis kadar air dan kadar alkoholnya. Analisis kadar air dilakukan dengan merujuk pada AOAC (2005). Mula-mula cawan porselen dikeringkan selama 30 menit di dalam oven dengan suhu $100-105^{\circ} \mathrm{C}$. Kemudian didinginkan dalam desikator selama 10 menit, lalu timbang cawan kering. Selanjutnya sampel bahan tape ketan hitam intsan diambil sebanyak 5 gram pada cawan porselen yang telah diketahui berat timbangannya. Kemudian dikeringkan selama 5-6 jam dengan suhu $105^{\circ} \mathrm{C}$. Selanjutnya cawan dan sampel didinginkan dalam desikator selama 20 menit dan ditimbang. Kemudian dilakukan pengovenan sampai berat konstan. Lalu dihitung dengan menggunakan rumus:

$$
\text { Kadar Air }(\% b b)=\frac{c-(a-b)}{c} \times 100 \%
$$

Keterangan :

$\mathrm{a}=$ berat cawan dan sampel akhir $(\mathrm{g})$

$\mathrm{b}=$ berat cawan $(\mathrm{g})$

$\mathrm{c}=$ berat cawan dan sampel awal $(\mathrm{g})$

Analisis kadar alkohol dalam tape ditentukan sebagai asam asetat dengan titrasi alkalimetri menggunakan larutan standar $\mathrm{NaOH} 0,1 \mathrm{~N}$ yang sudah distandardisasi lebih dahulu dengan asam oksalat (Sutanto dan Martono, 2006). Tape ketan hitam instan ditimbang sebanyak 20 gram kemudian diseduh dengan menggunakan air mendidih $\left(100^{\circ} \mathrm{C}\right)$ dengan volume $20 \mathrm{ml}$. Lalu didiamkan hingga dingin $( \pm 15$ menit). Selanjutnya, sari tape ketan diambil sebanyak $2 \mathrm{ml}$ dan diencerkan dalam labu takar $100 \mathrm{ml}$. Kemudian sari tape ketan hitam yang telah diencerkan dipindahkan dengan menggunakan pipet ukur sebanyak $20 \mathrm{ml}$ ke dalam labu Erlenmeyer $100 \mathrm{ml}$ dan ditetesi indikator phenopthalien sebanyak 2 tetes. Sampel kemudian dititrasi dengan menggunakan larutan standar $\mathrm{NaOH} 0,1 \mathrm{~N}$ yang sudah distandardisasi lebih dahulu dengan asam oksalat hingga muncul perubahan warna menjadi pink.

Pengujian terhadap karakteristik sensori pada tape ketan hitam instan dilakukan dengan menggunakan uji hedonik oleh 15 orang panelis agak terlatih. Sampel yang diujikan adalah sampel kering tape ketan hitam instan dan sampel tape ketan hitam instan yang telah diseduh dengan menggunakan air mendidih $\left(95^{\circ} \mathrm{C}\right)$ dan didiamkan selama 20 menit. Atribut penilaian dilakukan terhadap warna, rasa, aroma, tekstur, dan kenampakan tape ketan hitam instan.

Efektivitas pengeringan dalam mengendalikan jumlah mikroorganisme pada tape ketan hitam instan dilakukan melalui analisis jumlah mikroorganisme, penentuan TPC (Total Plate Count) dengan metode agar tuang. Prinsip metode ini adalah sel bakteri dalam sampel ditumbuhkan dalam medium agar dan diinkubasi selama 24 - 48 jam. Sel bakteri akan tumbuh membentuk koloni yang dapat dilihat secara visual sehingga dapat langsung dihitung. Mula-mula semua alat yang akan digunakan disterilisasi, kemudian disiapkan $1 \mathrm{gram}$ sampel (tape ketan hitam hasil penjemuran, pengovenan dan microwave oven). Kemudian dilakukan pengenceran sampel dengan menggunakan $\mathrm{NaCl}$ steril hingga pengenceran $10^{-5}$. Lalu dituangkan $1 \mathrm{ml}$ sampel yang telah diencerkan dan $10 \mathrm{ml}$ medium agar PCA (Plate Count Agar) cair yang bersuhu $40-48^{\circ} \mathrm{C}$ pada cawan petri. Medium dan inokulum diaduk dengan diputar selama $5-10$ detik. Setelah medium agar mengeras kemudian dibalik dan diinkubasi selama 2 hari pada suhu $30^{\circ} \mathrm{C}$. Kemudian dilakukan perhitungan jumlah koloni secara manual. Data yang digunakan pada penelitian ini adalah data dengan pengenceran terkecil karena data tidak bersifat homogen. Jumlah koloni dihitung dengan menggunakan rumus berikut:

$$
\text { Jumlah koloni per ml }(\mathrm{Cfu} / \mathrm{gram})=\sum \text { koloni } \mathrm{x} \frac{1}{\text { faktor pengenceran }}
$$




\section{HASIL DAN PEMBAHASAN \\ Karakteristik Sensori Tape Ketan Hitam Instan}

Warna merupakan faktor utama dalam menentukan tingkat kesukaan konsumen. Kombinasi warna sangat membantu dalam selera makan konsumen (Margaretha dan Japarianto, 2012). Proses pengeringan dapat menyebabkan terjadinya pencoklatan non-enzimatis (browning enzimatis). Reaksi pencoklatan ini disebabkan oleh adanya gula pasir yang ditambahkan secara langsung ke dalam bahan sebelum fermentasi tape ketan hitam instan. Selain itu, kandungan gula juga secara alami terdapat dalam tape ketan hitam.

Warna tape ketan hitam instan yang telah dikeringkan dengan berbagai metode pengeringan adalah ungu tua pekat. Panelis menilai tidak ada perbedaan signifikan pada warna tape ketan hitam instan yang dikeringkan baik dengan penjemuran, pengovenan, microwave oven, seperti disajikan pada tabel 1. Hal ini diduga karena suhu pengeringan yang digunakan tidak terlalu tinggi. Menurut Syafridawati (1991), suhu yang tidak terlalu tinggi menyebabkan komponen gula yang mengalami pencoklatan tidak banyak.

Tabel1. Hasil Uji Hedonik Warna Tape Ketan Hitam Instan pada Beberapa Metode Pengeringan

\begin{tabular}{lcc}
\hline \multirow{2}{*}{ Perlakuan Pengeringan } & \multicolumn{2}{c}{ Nilai Skor Rata-rata warna tape ketan hitam instan } \\
\cline { 2 - 3 } & Sampel Kering & Sampel Basah (setelah diseduh) \\
\hline Penjemuran & $3,20^{\mathrm{tn}}$ & $3,10^{\mathrm{tn}}$ \\
\hline Oven & $2,97^{\mathrm{tn}}$ & $3,17^{\mathrm{tn}}$ \\
\hline Microwave oven & $3,00^{\mathrm{tn}}$ & $3,00^{\mathrm{tn}}$ \\
\hline
\end{tabular}

Warna tape ketan hitam instan seduh yang paling disukai oleh konsumen adalah yang dikeringkan dengan oven. Warna tape ketan hitam instan ini adalah ungu tua mengkilap. Secara alami, dalam beras ketan hitam terdapat zat warna antosianin yang dapat digunakan sebagai pewarna alami pada makanan. Warna beras ketan hitam disebabkan oleh sel-sel pada kulit ari yang mengandung antosianin (Nailufar dkk., 2012). Antosianin dalam tape ketan hitam instan tidak memudar dengan adanya fermentasi begitu juga setelah pengeringan, baik dengan menggunkanan metode pengeringan penjemuran, oven maupun microwave oven. Hal ini disebabkan karena waktu yang relatif sebentar dan suhu yang digunakan tidak terlalu tinggi. Menurut Herudiyanto (2008), karotenoid dan antosianin akan berubah selama proses pengeringan. Semakin tinggi suhu dan semakin lama waktu pengeringan, menyebabkan semakin banyak perubahan zat warna. Penurunan total antosianin dapat terjadi dan dipengaruhi oleh beberapa faktor, antara lain cahaya, oksigen dan suhu. Penurunan total antosianin akan berpengaruh pada aktivitas antioksidan ketan hitam (Nailufar dkk., 2010).

Uji hedonik terhadap rasa dilakukan dengan cara menyeduh tape ketan hitam instan dengan menggunakan air mendidih $\left(95^{\circ} \mathrm{C}\right)$ lalu didiamkan selama 15 menit. Panelis menilai bahwa terdapat perbedaan signifkan pada rasa tape ketan hitam instan yang dikeringkan dengan cara berbeda. Hasil pengujian menunjukkan bahwa rasa yang paling disukai oleh konsumen adalah tape ketan hitam yang dikeringkan dengan penjemuran karena memiliki nilai rata-rata paling tinggi, seperti disajikan pada tabel 2 .

Tabel 2. Hasil Uji Hedonik Rasa Tape Ketan Hitam Instan pada Beberapa Metode Pengeringan

\begin{tabular}{lc}
\hline Perlakuan Pengeringan & Nilai Skor Rata-rata Rasa Tape ketan hitam instan \\
\hline Penjemuran & $2,63^{\mathrm{b}}$ \\
\hline Oven & $2,19^{\mathrm{C}}$ \\
\hline
\end{tabular}


Microwave oven

$1,97^{\mathrm{a}}$

Ket. : notasi yang berbeda menunjukkan adanya perbedaan signifikan pada taraf $1 \%$ dan $5 \%$

Tape ketan hitam mempunyai rasa manis, sedikit asam, sedikit alkohol, dan falvor yang spesifik karena adanya ester-ester (Sutanto dan Martono, 2006). Panelis menilai bahwa rasa tape ketan hitam instan yang dikeringkan dengan penjemuran dan oven cenderung sama dengan tape ketan hitam pada umumnya, tidak ada penyimpangan rasa akibat reaksi pencoklatan nonenzimatis ataupun akibat proses karamelisasi gula dalam bahan. Hal ini disebabkan karena suhu yang dihasilkan oleh sinar matahari cukup rendah juga suhu oven $50^{\circ} \mathrm{C}$ (Winangsih dkk., 2013).

Rasa pada tape ketan hitam instan yang dikeringkan dengan microwave oven, yakni manis, agak pahit dan agak asam. Sensasi rasa agak pahit, menyimpang dari rasa tape ketan hitam pada umumnya. Energi panas yang tinggi dari gelombang elektromagnetik microwave oven menyebabkan adanya reaksi pencoklatan non-enzimatis yang menimbulkan rasa yang menyimpang, yakni pahit. Gelombang elektromagnetik yang digunakan microwave oven adalah $2,5 \mathrm{GHz}$. Gelombang ini merambat secara radiasi. Gelombang pada frekuensi tersebut akan diserap oleh material-material seperti air, lemak dan gula. Hal ini menyebabkan atom-atom pada material tadi berotasi dan saling bertabrakan sehingga timbulah energi panas yang tinggi.

Aroma adalah reaksi dari makanan yang akan mempengaruhi konsumen sebelum konsumen menikmati makanan, konsumen dapat mencium makanan tersebut (Margaretha dan Japarianto (2012). Aroma (flavor) yang khas pada tape ketan hitam instan berasal dari hidrolisa amilosa dan amilopektin oleh enzim amilase yang berasal dari ragi yang kemudian dipecah lagi menjadi asam piruvat, asam organik lain, dan alkohol. Reaksi antara alkohol dengan asam-asam yang terbentuk akan menghasilkan komponen flavor (Syafridawati, 1991).

Tabel 3. Hasil Uji Hedonik Aroma Tape Ketan Hitam Instan dengan Beberapa Metode Pengeringan

\begin{tabular}{ccc}
\hline \multirow{2}{*}{$\begin{array}{c}\text { Perlakuan } \\
\text { Pengeringan }\end{array}$} & \multicolumn{2}{c}{ Nilai Skor Rata-rata Aroma Tape Ketan Hitam Instan } \\
\cline { 2 - 3 } & Sampel Kering & Sampel Basah (setelah diseduh) \\
\hline Penjemuran & $2,87^{\text {tn }}$ & $2,70^{\text {tn }}$ \\
\hline Oven & $2,63^{\text {tn }}$ & $2,80^{\text {tn }}$ \\
\hline Microwave oven & $2,50^{\text {tn }}$ & $2,37^{\text {tn }}$ \\
\hline \multicolumn{2}{c}{$:$ data tidak berbeda signifikan pada taraf $1 \%$ dan $5 \%$}
\end{tabular}

Aroma termasuk komponen volatil yang mudah menguap bila dipanaskan atau dikeringkan (Syaridawati, 1991). Aroma yang dihasilkan oleh tape ketan hitam instan cenderung tidak menyengat karena dalam keadaan kering. Tape ketan hitam instan yang dikeringkan dengan beberapa metode pengeringan menunjukan tidak adanya perbedaan yang signifikan pada atribut aroma, seperti tersaji pada tabel 3 . Hal ini berarti bahwa aroma yang dihasilkan oleh tape ketan hitam instan baik yang dikeringkan dengan penjemuran, oven maupun microwave oven tidak memiliki perbedaan yang nyata menurut penilaian panelis. Nilai rata-rata tertinggi terhadap kesukaan aroma dimiliki oleh tape ketan hitam instan yang dikeringkan menggunakan oven. Menurut Labuza (1977 dalam Syafridawati, 1991) semakin tinggi suhu pengeringan, komponen bahan (misalnya gula pereduksi, asam, alkohol, dan lain-lain) yang hilang semakin tinggi. Akibatnya, aroma tape ketan hitam instan tidak menyengat dan tidak menyebabkan perbedaan tingkat kesukaan oleh konsumen. Hal ini sejalan dengan kadar alkohol tape ketan hitam instan yang tidak menunjukkan adanya perbedaan yang signifikan.

Tekstur makanan beragam, antara lain halus atau tidak, cair atau padat, keras atau lembut, kering atau lembab. Tingkat tipis dan halus serta bentuk makanan dapat dirasakan lewat tekanan dan gerakan dari reseptor di mulut (Margaretha dan Japarianto, 2012). Pada penelitian ini, tekstur tape ketan hitam instan yang diamati adalah tingkat kesukaan konsumen terhadap keras atau 
lembut dan kering atau lembabnya tape ketan hitam instan, baik pada sampel kering maupun sampel yang telah diseduh.

Tape ketan hitam instan yang dikeringkan dengan penjemuran memiliki nilai rata-rata paling tinggi dengan tekstur yang keras dan agak kasar. Pengujian terhadap sampel kering tape ketan hitam instan menunjukkan bahwa tekstur tape ketan hitam instan tidak memiliki perbedaan yang nyata seperti ditunjukkan pada tabel 4. Hal ini diduga karena kadar air tape ketan hitam instan dari ketiga perlakuan hampir sama.

Tabel 4. Hasil Uji Hedonik Tekstur Tape Ketan Hitam Instan pada Beberapa Metode Pengeringan

\begin{tabular}{lcc}
\hline \multirow{2}{*}{$\begin{array}{c}\text { Perlakuan } \\
\text { Pengeringan }\end{array}$} & \multicolumn{2}{c}{ Nilai Skor Rata-rata Rasa Tape Ketan Hitam Instan } \\
\cline { 2 - 3 } & Sampel Kering & Sampel Basah (setelah diseduh) \\
\hline Penjemuran & $2,90^{\text {tn }}$ & $2,83^{\text {tn }}$ \\
\hline Oven & $2,80^{\text {tn }}$ & $2,43^{\text {tn }}$ \\
\hline Microwave oven & $2,43^{\text {tn }}$ & $2,43^{\text {tn }}$ \\
\hline
\end{tabular}

Selain warna dan aroma, faktor utama yang diperhatikan konsumen saat pertama kali menyukai produk pangan adalah kenampakan keseluruhannya. Aspek kenampakan yang dinilai pada uji hedonik ini adalah tingkat kesukaan konsumen pada kenampakan keseluruhan dan kebersihan tape ketan hitam instan. Kesegaran dan kebersihan dari makanan yang disajikan adalah contoh penting yang akan mempengaruhi kenampakan makanan baik atau tidak untuk dinikmati (Margaretha dan Japarianto, 2012).

Tabel 4. Hasil Uji Hedonik Kenampakan Tape Ketan Hitam Instan pada Beberapa Metode Pengeringan

\begin{tabular}{ccc}
\hline \multirow{2}{*}{$\begin{array}{c}\text { Perlakuan } \\
\text { Pengeringan }\end{array}$} & \multicolumn{2}{c}{ Nilai Skor Rata-rata Kenampakan Tape Ketan Hitam Instan } \\
\cline { 2 - 3 } & Sampel Kering & Sampel Basah (setelah diseduh) \\
\hline Penjemuran & $2,97^{\text {tn }}$ & $2,90^{\text {tn }}$ \\
\hline Oven & $2,90^{\text {tn }}$ & $2,83^{\text {tn }}$ \\
\hline Microwave oven & $2,47^{\text {tn }}$ & $2,77^{\text {tn }}$ \\
\hline \multicolumn{2}{c}{${ }^{\text {tn }}:$ data tidak berbeda signifikan pada taraf 1\% dan $5 \%$}
\end{tabular}

Secara umum, kenampakan tape ketan hitam instan baik, tidak rusak dan bersih. Nilai ratarata kenampakan tape ketan hitam instan yang dikeringkan dengan penjemuran adalah yang tertinggi berdasarkan penilaian panelis. Namun demikian, panelis menilai tidak terdapat perbedaan signifikan pada kenampakan tape ketan hitam instan baik pada sampel kering maupun basah (setelah diseduh). Hal ini berkaitan dengan warna tape ketan hitam instan yang tidak menunjukkan perbedaan yang signifikan antar perlakuan.

\section{Karakteristik Kimiawi}

Kadar air dalam bahan makanan akan sangat mempengaruhi karakteristik fisik, kimia maupun biologi. Secara fisik dapat menentukan warna, penampakan, tekstur dan citarasa makanan. Secara kimia dapat mempengaruhi kadar air makanan. Serta secara biologi dapat berpengaruh terhadap aktivitas mikroorganisme dalam bahan pangan tersebut. Hasil analisis sidik ragam pada hasil kadar air tersebut, tidak terdapat perbedaan yang nyata antar perlakuan pengeringan (Tabel 6). Hal ini disebabkan karena kadar air tape ketan hitam instan yang dikeringkan dengan penjemuran menjadi acuan bagi perlakuan yang lain.

Tape ketan hitam sebelum dikeringkan memiliki kadar air sebesar 54,16\%. Kemudian setelah mengalami pengeringan baik dengan menggunakan metode penjemuran, oven maupun microwave oven memiliki kadar air masing-masing 7,43\%; 7,57\% dan $6,35 \%$ seperti tersaji pada 
Tabel 6. Kadar air tape ketan hitam mengalami penurunan yang sangat tinggi setelah dikeringkan. Hal ini dilakukan untuk meningkatkan masa simpan tape ketan hitam instan. Makanan yang dikeringkan atau dikeringbekukan memiliki kestabilan yang tinggi pada penyimpanan apabila rentang kandungan airnya $5-15 \%$ (deMan, 1997).

Tabel 6. Kadar Air Tape Ketan Hitam Instan dengan Beberapa Metode Pengeringan

Perlakuan Pengeringan

Kadar Air Tape Ketan Hitam Instan (\%)

\begin{tabular}{cc}
\hline Penjemuran & $7,43^{\text {tn }}$ \\
\hline Oven & $7,57^{\text {tn }}$ \\
\hline Microwave Oven & $6,35^{\text {tn }}$ \\
\hline \multicolumn{2}{c|}{$:$ data tidak berbeda signifikan pada taraf $1 \%$ dan $5 \%$}
\end{tabular}

Aktivitas mikroorganisme yang berperan dalam proses fermentasi pada tape ketan hitam ditandai dengan produksi alkohol. Semakin lama waktu fermentasi maka kadar alkohol tape ketan akan semakin meningkat. Peragian (fermentasi) sayur-sayuran, buah-buahan atau biji-bijian akan berhenti bila kadar alkohol telah mencapai 14 - 16\% (Fessenden \& Fessenden, 1997 dalam Yulianti, 2014). Tetapi, dengan adanya pengeringan, alkohol dapat menguap karena bersifat volatil (Syafridawati, 1991).

Proses fermentasi yang berlangsung selama pembuatan tape pada dasarnya merupakan gabungan dari empat tahap reaksi penguraian (Hesseltine, 1979 dalam Syafridawati, 1991), yaitu molekul-molekul pati pada beras ketan hitam akan dipecah menjadi dekstrin dan gula-gula sederhana, proses ini merupakan proses hidrolisa enzimatik. Selanjutnya, gula yang terbentuk dihidrolisa menjadi alkohol. Alkohol akan diubah menjadi asam-asam organik oleh bakteri Pediococcus dan Acetobacter melalui proses oksidasi alkohol, dan sebagian asam organik akan bereaksi dengan alkohol membentuk komponen citarasa tape, yaitu ester.

Tabel 7. Kadar Alkohol Tape Ketan Hitam Instan pada Beberapa Metode Pengeringan

\begin{tabular}{|c|c|}
\hline Perlakuan Pengeringan & Kadar Alkohol Tape Ketan Hitam Instan(\%) \\
\hline Penjemuran & 0,39 \\
\hline Oven & 0,26 \\
\hline Microwave Oven & 0,35 \\
\hline
\end{tabular}

Hasil analisis sidik ragam menunjukkan bahwa tidak ada perbedaan signifikan kadar alkohol antar perlakuan pengeringan, seperti tersaji pada Tabel 7. Kadar alkohol tape ketan hitam instan masih dalam batas halal karena memiliki kisaran kadar alkohol $0,26 \%-0,39 \%$. Suatu makanan akan dikatakan tidak halal (haram) apabila kandungan alkohol didalamnya lebih dari $1 \%$. Fatwa MUI No. 4 Tahun 2003 tentang Standarisasi Fatwa Halal menyebutkan bahwa minuman keras yang dibuat dari air perasan tape dengan kandungan etanol minimal $1 \%$ termasuk kategori khamr. Khamr adalah setiap yang memabukkan, baik berupa minuman, makanan maupun lainnya. Hukum khamr adalah haram. Kemudian dijelaskan lebih lanjut, bahwa tape dan air tape tidak termasuk khamr, kecuali apabila memabukkan.

\section{Efektivitas Pengeringan dalam Mengendalikan Mikroorganisme}

Metode pengawetan dengan pengeringan didasarkan pada prinsip bahwa mikroorganisme dan reaksi-reaksi kimia hanya terjadi jika air tersedia dalam jumlah cukup. Jumlah kandungan air 
dalam bahan hasil pertanian akan mempengaruhi daya tahan suatu bahan tersebut terhadap serangan mikroorganisme. Daya tahan suatu bahan terhadap kontaminasi mikroorganisme dapat ditingkatkan dengan cara menghilangkan atau menguapkan sebagian air pada bahan sehingga mencapai kadar air tertentu (Pramono, 2006).

Efektivitas pengeringan dalam mengendalikan mikroorganisme dilakukan dengan cara menghitung jumlah mikroorganisme pada tape ketan hitam instan menggunakan metode Total Plate Count (TPC). Jumlah koloni pada tape ketan hitam instan yang dikeringan dengan penjemuram memiliki jumlah yang paling tinggi, yakni $177 \times 10^{3} \mathrm{Cfu} / \mathrm{ml}$. Rata-rata jumlah mikroorganisme tape ketan hitam instan yang dikeringkan dengan oven adalah $72 \times 10^{3} \mathrm{Cfu} / \mathrm{ml}$; microwave oven $68,5 \times 10^{3} \mathrm{Cfu} / \mathrm{ml}$, seperti tersaji pada Gambar 1 . Hal ini menunjukkan bahwa terdapat penurunan jumlah mikroorganisme ketika tape ketan hitam instan dikeringkan dengan oven dan microwave oven. Menurut Primawisdawati (2010) jumlah total mikroorganisme selama pemanasan dengan menggunakan oven microwave semakin menurun dengan semakin lamanya waktu pemanasan.

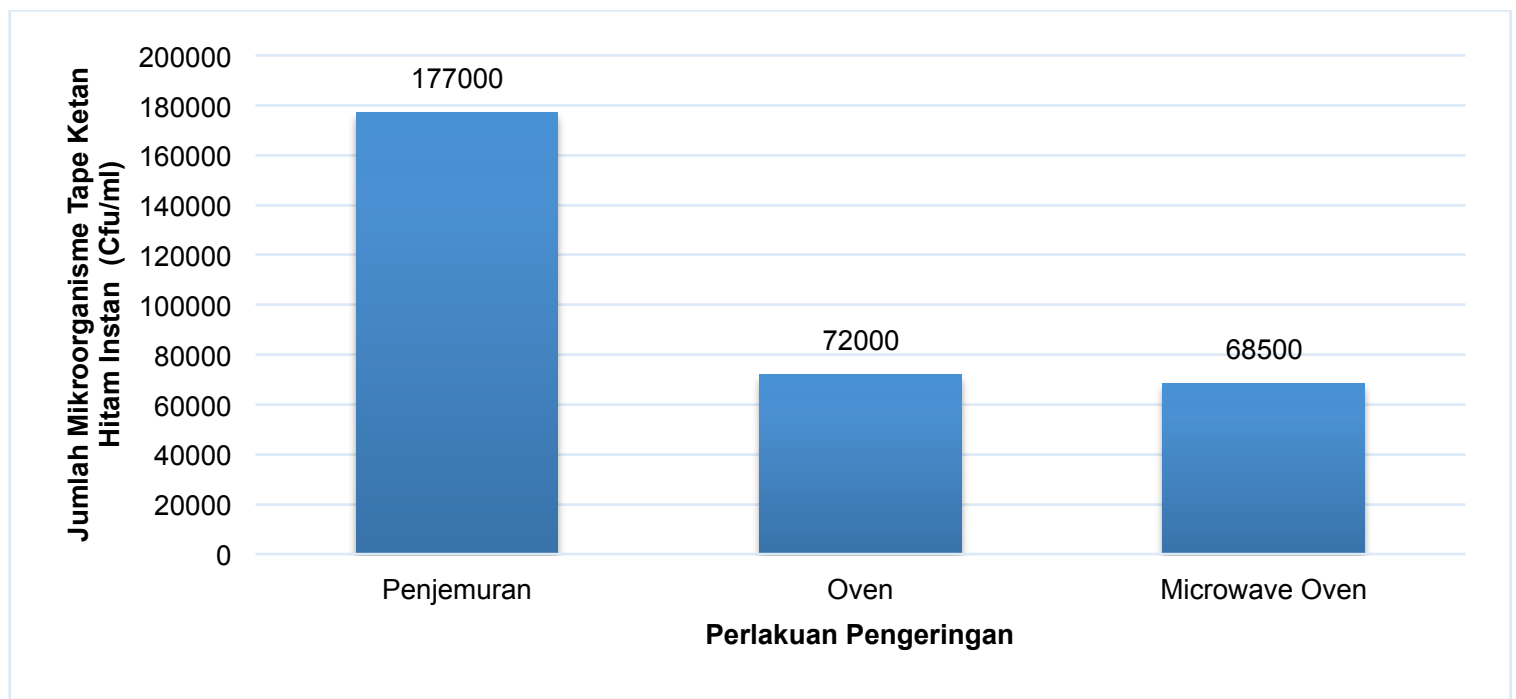

Gambar 1. Grafik Jumlah Mikroorganisme Tape Ketan Hitam Instan pada Beberapa Metode Pengeringan

Oleh karena itu, pengeringan dengan menggunakan alat pengering lebih aman dari kontaminasi mikroorganisme yang berasal dari udara terbuka pada saat penjemuran. Hal ini menunjukkan bahwa penggunaan oven dan microwave oven dapat mengendalikan dan menekan jumlah mikroorganisme pada tape ketan hitam instan. Pengeringan dengan penjemuran langsung memiliki beberapa kekurangan seperti jagung yang dapat terkontaminasi langsung dengan kerikil, debu dan bakteri, juga pengeringan membutuhkan waktu yang lama (Apriadi, 2011).

\section{KESIMPULAN}

1. Tape ketan hitam instan yang dikeringkan dengan penjemuran paling disukai konsumen pada atribut warna dan aroma (sampel kering), rasa, tekstur dan kenampakan (sampel setelah diseduh). Karakteristik kimia tape ketan hitam instan yang dikeringkan dengan menggunakan penjemuran (kadar air 7,43\%; kadar alkohol 0,39\%), oven (kadar air 7,57\%; kadar alkohol $0,26 \%$ ) dan microwave oven (kadar air 6,35\%; kadar alkohol 0,35\%).

2. Pengeringan menggunakan oven dan microwave oven dapat mengendalikan mikroorganisme pada tape ketan hitam instan.

\section{DAFTAR PUSTAKA}


Adipura, A. (2014). Studi Eksperimen Pembuatan Selai dengan Bahan Dasar Tape Ketan Hitam dan Tape Ketan Kuningan serta Daya Terima Konsumennya. (Thesis). Universitas Pendidikan Indonesia.

Apriadi, Amanah, H. Z. \& Bintoro, N. (2011). Analisis Perpindahan Panas dan Massa Proses Pengeringan Jagung Tongkol pada Beberapa Metode Pengeringan Sederhana. Prosiding Seminar Nasional PERTETA 2011. Fakultas Teknologi Pertanian Universitas Gajah Mada.

Datta, A. K. (2002). Simulation-based design of food products and processes. Di dalam: WeltiChanes, J., Barbosa-Cánovas, G.V., Aguilera, J.M. Engineering and Food for The 21st Century. USA: CRC Press, pp 831-846.

deMan, J. M. (1997). Kimia Makanan Edisi Kedua. Bandung: Penerbit ITB.

Fatwa Majelis Ulama Indonesia Nomor 4 Tahun 2003 tentang Standardisasi Fatwa Halal. Majelis Ulama Indonesia Komisi Fatwa.

Haryati, Estiasih, E., Heppy, F., \& Ahmadi, K. (2015). Pendugaan Umur Simpan Menggunakan Metode Accelerated Shelf-Life Testing (ASLT) dengan Pendekatan Arrhenius pada Produk Tape Ketan Hitam Khas Mojokerto Hasil Sterilisasi Jurnal Pangan dan Agroindustri. Vol. 3 (1), hlm. $156-165$.

Herudiyanto, M. S. (2008). Pengantar Teknologi Pengolahan Pangan. Bandung: Widya Padjajaran. Margaretha, F. S. \& Japarianto, E. (2012). Analisa Pengaruh Food Quality dan Brand Image Terhadap Keputusan Pembelian Roti Kecik Toko Roti Ganep's di Kota Solo.

Maskan, M. (2000). Microwave/air and microwave @nish drying of banana. Journal of Food Engineering 44. hlm. $71-78$.

Nailufar, A. A,, Basito, \& Anam, C. (2012). Kajian Karakteristik Ketan Hitam (Oryza sativa glutinosa) pada Beberapa Jenis Pengemas Selama Penyimpanan. Jurnal Teknosains Pangan. Vol 1 (1), hlm. $121-132$.

Pramono, S. 2006. Penanganan Pasca Panen Dan Pengaruhnya Terhadap Efek Terapi Obat Alami. Prosiding Seminar nasional Tumbuhan Obat Indonesia XXVIII, Bogor, 15-18 Sept.2005. hlm. $1-6$.

Primawisdawati. (2010). Cemaran Bacillus spp. pada Nasi Putih di Wilayah Darmaga, Bogor Serta Pengaruh Pemanasan dengan Oven Microwave (Skripsi). Fakultas Teknologi Pertanian Institut Pertanian Bogor.

Sutanto, T. D. \& Martono, A. (2006). Studi Kandungan Etanol dalam Tapai Hasil Fermentasi Beras Ketan Hitam dan Putih Jurnal Gradien. Vol. 2 (1).

Syafridawaty. (1991). Studi Pembuatan Tape Ketan Instan dari Beberapa Jenis Beras Ketan dan Suhu Pengeringan Beku (Skripsi). Fakultas Teknologi Pertanian Institut Pertanian Bogor, Bogor.

Winangsih, Prihastanti, E. \& Parman, S. (2013). Pengaruh Metode Pengeringan Terhadap Kualitas Simplisia Lempuyang Wangi (Zingiber Aromaticum L.). Buletin Anatomi dan Fisiologi. Vol. 21 (1), hlm. $19-25$.

Yulianti, C. H. (2014). Uji Beda Kadar Alkohol Pada Tape Beras Ketan Hitam Dan Singkong. Jurnal Teknika. Vol. 6 (1), hlm. $531-536$. 